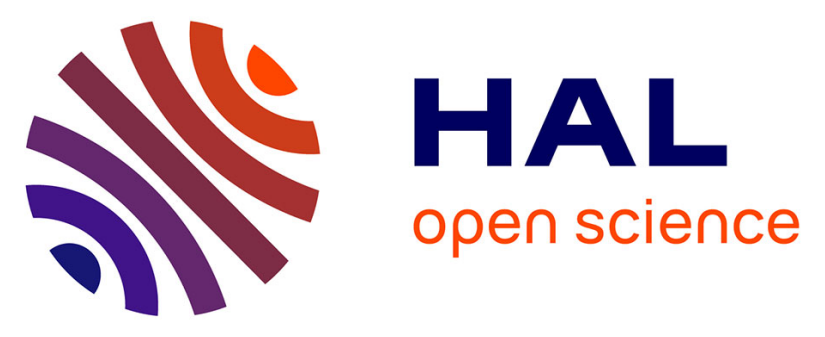

\title{
Expression and Activity of Serum Response Factor Is Required for Expression of the Muscle-determining Factor MyoD in Both Dividing and Differentiating Mouse C2C12 Myoblasts
}

Cécile Gauthier-Rouvière, Marie Vandromme, David Tuil, Nicole Lautredou, May Morris, Marielle Soulez, Axel Kahn, Anne Fernandez, Ned J. Lamb

\section{To cite this version:}

Cécile Gauthier-Rouvière, Marie Vandromme, David Tuil, Nicole Lautredou, May Morris, et al.. Expression and Activity of Serum Response Factor Is Required for Expression of the Muscle-determining Factor MyoD in Both Dividing and Differentiating Mouse C2C12 Myoblasts. Molecular Biology of the Cell, 1996, 7, pp.719 - 729. 10.1091/mbc.7.5.719 . hal-02872109

\author{
HAL Id: hal-02872109 \\ https://hal.science/hal-02872109
}

Submitted on 10 Mar 2021

HAL is a multi-disciplinary open access archive for the deposit and dissemination of scientific research documents, whether they are published or not. The documents may come from teaching and research institutions in France or abroad, or from public or private research centers.
L'archive ouverte pluridisciplinaire HAL, est destinée au dépôt et à la diffusion de documents scientifiques de niveau recherche, publiés ou non, émanant des établissements d'enseignement et de recherche français ou étrangers, des laboratoires publics ou privés. 


\title{
Expression and Activity of Serum Response Factor Is Required for Expression of the Muscle-determining Factor MyoD in Both Dividing and Differentiating Mouse C2C12 Myoblasts
}

\author{
Cécile Gauthier-Rouviere, ${ }^{*}$ Marie Vandromme, ${ }^{*}$ David Tuil, ${ }^{+}$ \\ Nicole Lautredou, ${ }^{*}$ May Morris, ${ }^{*}$ Marielle Soulez, ${ }^{+}$Axel Kahn, ${ }^{+}$ \\ Anne Fernandez, ${ }^{* \ddagger}$ and Ned Lamb*
}

*Cell Biology Unit, Centre de Recherche de Macromoléculaire, CNRS-INSERM, BP 5051, 34033

Montpellier Cedex, France; and Institut Cochin de Genétique Moléculaire, INSERM U129, 75014

Paris, France

Submitted December 10, 1995; Accepted February 15, 1996

Monitoring Editor: Keith R. Yamamoto

To understand the mechanism by which the serum response factor (SRF) is involved in the process of skeletal muscle differentiation, we have assessed the effect of inhibiting SRF activity or synthesis on the expression of the muscle-determining factor MyoD. Inhibition of SRF activity in mouse myogenic $\mathrm{C} 2 \mathrm{C} 12$ cells through microinjection of either the SRE oligonucleotide (which acts by displacing SRF proteins from the endogenous SRE sequences), purified SRF-DB (a 30-kDa portion of SRF containing the DNAbinding domain of SRF, which acts as a dominant negative mutant in vivo), or purified anti-SRF antibodies rapidly prevents the expression of MyoD. Moreover, the rapid shutdown of MyoD expression after in vivo inhibition of SRF activity is observed not only in proliferating myoblasts but also in myoblasts cultured under differentiating conditions. Additionally, by using a cellular system expressing a glucocorticoid-inducible antisense-SRF (from aa 74 to 244) we have shown that blocking SRF expression by dexamethasone induction of antisense SRF results in the lack of MyoD expression as probed by both immunofluorescence and Northern blot analysis. Taken together these data demonstrate that SRF expression and activity are required for the expression of the muscle-determining factor MyoD.

\section{INTRODUCTION}

The serum response factor (SRF) belongs to the MADS (MCM1-agamous-ARG80-deficiens-SRF)-box transcription factors family (Nurrish and Treisman, 1995) and binds a sequence called SRE (serum response element) (Prywes and Roeder, 1987; Treisman, 1987; Norman et al., 1988). This serum regulatory element is found in the promoter region of many growth factor-stimulated immediate early genes, c-fos being the first described (Treisman, 1985; Gilman et al., 1986; Treisman and Ammerer, 1992). SRE is the prototype of a large

\footnotetext{
‡ Corresponding author.
}

family of upstream elements within mammalian promoters that have a core consensus sequence of CC(A/ T) 6 GG known as CArG box (Minty and Kedes, 1986; Taylor et al., 1988). In particular, many muscle-specific genes contain this CArG sequence in their promoter region (Minty and Kedes, 1986; Taylor et al., 1988; Klamut et al., 1990; Ernt et al., 1991) and in some of them, these sequences were shown to be activating elements essential for the expression of muscle-specific markers (Mohun et al., 1987; Tuil et al., 1993).

SRF binds to CArG motifs present in the promoter regions of the sarcomeric $\alpha$-actin genes (Boxer et al., 1988 ) and the chicken cardiac myosin light-chain gene (Papadopoulos and Crow, 1993). Muscle-specific 
(CArG) and serum-responsive (SRE) promoter elements are functionally interchangeable, showing again that these two motifs could bind the same factor in vivo (Boxer et al., 1988; Taylor et al., 1989; Tuil et al., 1990). Moreover, Mohun et al. (1991) have reported that SRF is implicated both in muscle-specific gene expression and serum-responsive transcription in Xenopus embryos.

SRF is required for all SRE functions in vivo as revealed by SRE mutagenesis experiments that reduce or block SRF binding (Treisman, 1990), microinjection of SRE oligonucleotide or SRF-DB (a portion of SRF protein from amino acids 113-265 containing the DNA-binding and dimerization domains), and the inhibition of c-fos induction and cell growth when SRF is depleted from cell nuclei by cytoplasmic microinjection of SRF-specific antibodies (Gauthier-Rouviere et al., 1991a,b, 1993). Moreover, through microinjection of anti-SRF antibodies, we have shown that SRF, in addition to its role in cell proliferation, is also implicated in skeletal muscle differentiation of rat L6 and mouse C2 cell lines. Inhibition of SRF activity was found to block myoblast to myotube transition and prevent the expression of two myogenic differentiation markers, myogenin and troponin $\mathrm{T}$ (Vandromme et al., 1992).

This early requirement for SRF in myogenesis led us to investigate whether SRF is implicated in the regulation of the muscle-specific regulatory gene MyoD, the expression of which in a large number of primary cells and cell lines is sufficient to convert these cells to skeletal myoblasts (Lassar et al., 1986; Tapscott et al., 1988; Choi et al., 1990). MyoD is a nuclear protein expressed in skeletal muscle cells and belongs to the family of muscle-specific basic helix-loop-helix proteins that includes myf-5, myogenin, and MRF-4. These proteins, through binding to the E-box (CANNTG) upon heterodimerization with other basic helix-loop-helix factors such as the ubiquitously expressed E12 and E47 proteins, act as a transcriptional activator of genes that encode skeletal muscle-specific proteins (Murre et al., 1989; Weintraub et al., 1991; Lassar et al., 1991). MyoD is a constitutive protein both in myoblasts and myotubes; we have therefore questioned whether inhibition of SRF expression or activity is capable of affecting MyoD expression. Through microinjection of either SRE oligonucleotide, purified SRF-DB, or anti-SRF antibodies we have shown that SRF activity is required for the expression of the muscle-determining factor MyoD. We observed a rapid shutdown of MyoD expression upon inhibition of SRF activity in proliferating myoblasts as well as in myoblasts cultured under differentiating conditions. Additionally, using a cell line containing an inducible antisense expression vector, we have confirmed that induction of antisense SRF led to the progressive extinction of endogenous SRF and the concomitant abo- lition of MyoD expression. Taken together these complementary approaches show that MyoD expression requires the presence and activity of SRF.

\section{MATERIALS AND METHODS}

\section{Cell Culture}

The myogenic mouse C2C12 cell line (Blau et al., 1983) was grown in DMEM supplemented with $10 \%$ fetal calf serum. Differentiation was induced by plating $\mathrm{C} 2 \mathrm{C} 12$ myoblasts at $10^{4}$ cells $/ \mathrm{cm}^{2}$ on plastic dishes in growth medium for 2 days and replacing the growth medium with differentiation medium (DMEM supplemented with $2 \%$ fetal calf serum). Three days after addition of the differentiation medium, $60-80 \%$ of the cells had differentiated into myotubes and greater than 99 of cells expressed MyoD and myogenin.

\section{Antisense SRF Cell Line Establishment and Culture}

$\mathrm{C} 2 \mathrm{CL} 2$ is a muscle clone derived from the mouse myogenic $\mathrm{C} 2 \mathrm{C} 12$ cell line stably transfected with plasmid P501, a plasmid that contains the cDNA encoding the human glucocorticoid receptor gene under the control of the Rous sarcoma virus promoter (Le Ricousse et al., in press).

Anti-6 is a clone generated in C2CL2 cells (described above) stably transfected with plasmid P504, a plasmid bearing the antisense SRF cDNA representing $517 \mathrm{bp}$ (corresponding to amino acids 74-244) of the human cDNA sequence under the control of mouse mammary tumor virus long terminal repeat (Soulez, Gauthier-Rouviere, Henzen, Vandromme, Lamb, Kahn, and Tuil, unpublished data).

C2CL2 or anti-6 cells were plated at 60,000 cells/dish in DMEM supplemented with $10 \%$ fetal calf serum with or without the glucocorticoid dexamethasone $\left(10^{-6} \mathrm{M}\right)$. In cells cultured with dexamethasone a supplementary addition of dexamethasone was performed $36 \mathrm{~h}$ after plating. After 3 days, cells were fixed and analyzed for SRF and MyoD expression (see below).

\section{Northern Blot Analysis}

Poly(A) ${ }^{+}$RNAs were isolated from at least 108 cells with a Fast Track Kit (Invitrogen, San Diego, CA). Northern blot analysis were performed as previously described (Concordet et al., 1993). Membranes were successively hybridized with the following randomly labeled probes: the $1.15-\mathrm{kb}$ human SRF C terminal cDNA fragment, the $1.8-\mathrm{kb}$ mouse MyoD cDNA fragment, and the R45 cDNA probe (corresponding to a fragment of human 18S rRNA). Hybridized membranes were scanned with a PhosphorImager (Molecular Dynamics, Sunnyvale, CA).

\section{Microinjection}

For microinjection studies, cells grown on plastic dishes were microinjected with either SRE oligonucleotide (5'-AGGATGTCCATATTAGGACATCTGC-3'), mutated SRE oligonucleotide (5'AGGATGTCCATATTAACTATTGATG- $\left.3^{\prime}\right) \quad(0.3 \mathrm{mg} / \mathrm{ml}$ in the needle), or purified SRF-DB (at 0.3 to $0.5 \mathrm{mg} / \mathrm{ml}$ in the needle) in a solution containing rabbit marker antibodies $(0.5 \mathrm{mg} / \mathrm{ml})$. Purified anti-SRF antibodies were injected alone into the cytoplasm of cells. After microinjection, cells were either kept in the same medium or transferred to differentiation medium and returned to the incubator. At different times cells were fixed and stained for MyoD expression and the presence of the marker antibodies.

\section{Immunofluorescence}

At various times after microinjection, cells were fixed for $5 \mathrm{~min}$ in $3.7 \%$ formalin (in phosphate-buffered saline) followed by a 30-s extraction in $-20^{\circ} \mathrm{C}$ acetone and rehydration in phosphate-buffered 
saline containing $0.1 \%$ bovine serum albumin. Cells were stained for injected rabbit marker antibody by using fluorescein-conjugated anti-rabbit antibody (1:200; Cappel, West Chester, PA) and for MyoD expression by using a monoclonal anti-MyoD antibody (1:20; a generous gift from Jim Hallman and Peter Dias in the Peter Houghton laboratory, St. Jude Children's Research Hospital, Memphis, TN) for $60 \mathrm{~min}$ and biotinylated anti-mouse (1:200; Amersham, Arlington Heights, IL) for 30 min and streptavidin-Texas Red (1:400, Amersham) for $30 \mathrm{~min}$. For SRF staining after anti-SRF antibody microinjection, cells were processed as previously described (Gauthier-Rouviere et al., 1991). The chromatin was stained with Hoechst $(0.1 \mu \mathrm{g} / \mathrm{ml}$; Sigma, St. Louis, MO) applied just before cells were mounted and observed by confocal laser scanning microscopy.

C2CL2 and anti- 6 cells were fixed as described above and stained for SRF expression as previously described (Gauthier-Rouviere et al., 1991) and MyoD expression as described above.

\section{Confocal Laser Scanning Microscopy}

Dual-channel Confocal Laser Scanning Microscopy was performed using the Leica CLSM equipped with a Krypton-Argon ion laser using two major emission lines at $488 \mathrm{~nm}$ for fluorescein isothiocyanate excitation and $568 \mathrm{~nm}$ for rhodamine or Texas Red excitation. Planapochromat lenses $(40 \times$ or $63 \times)$ were used and the untreated images were directly transferred from the VME bus of the Leica Motorola 68040 to a Silicon Graphics IRIS Indigo workstation (R3000). Images were deconvoluted, gamma mapped, and converted to SGI raster format using "convert" (18). Figures were assembled completely under SGI showcase 3.20 and printed directly as postscript files using a Kodak Colorease thermal sublimation printer (Rochester, NY).

\section{RESULTS}

\section{Inhibition of SRF Activity Rapidly Blocks MyoD Expression in C2C12 Myoblasts under Proliferating Conditions}

We have shown previously that injection of anti-SRF antibodies into C2 or L6 myoblasts impairs the differentiation of these two cell lines by preventing both myogenin expression and the myoblast-myotube transition (Vandromme et al., 1992). To investigate this early requirement of SRF in myogenesis, we questioned the potential implication of SRF in MyoD expression. MyoD that is a key regulator of myogenesis acts upstream of myogenin in promoting cells to differentiate and its expression is required to promote the differentiated phenotype. We chose to inhibit SRF activity by microinjection and examine the subsequent effect of this inhibition on the expression of MyoD. To inhibit SRF activity, subconfluent $\mathrm{C} 2 \mathrm{C} 12$ myoblasts growing under conditions that favor proliferation, were microinjected with either the SRE oligonucleotide (SRE sequence of the c-fos promoter that corresponds to the putative DNA binding site for SRF protein and acts inside cells by squelching SRF proteins) or purified SRF-DB (a 30-kDa portion of SRF containing only the DNA-binding domain of SRF and acting as a dominant negative mutant in vivo). At different times after injection, cells were fixed and the effect of SRF inhibition on MyoD expression was assessed by immunofluorescence. The muscle-determin- ing factor MyoD is expressed in 75-80\% of subconfluent proliferating $\mathrm{C} 2 \mathrm{C} 12$ myoblasts (as visible in the surrounding noninjected cells in the different panels of Figure 1). Figure 1A details the microinjection protocol and immunofluorescence analyses shown in Figure 1B. In Figure 1B, cells injected with SRE (visualized in panel $\mathrm{A}$ by staining for coinjected inert marker antibody) and fixed $4 \mathrm{~h}$ after microinjection show the complete absence of MyoD expression (Figure 1B, panel B). Cells were also stained with Hoechst, a specific stain for DNA, to allow identification of the nuclei in both microinjected and nonmicroinjected cells (Fig-

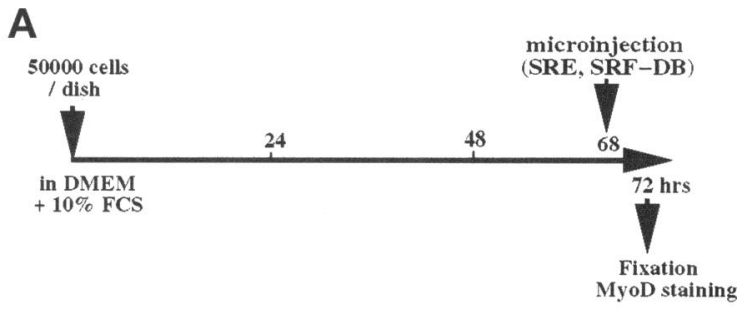

B
Marker IgG
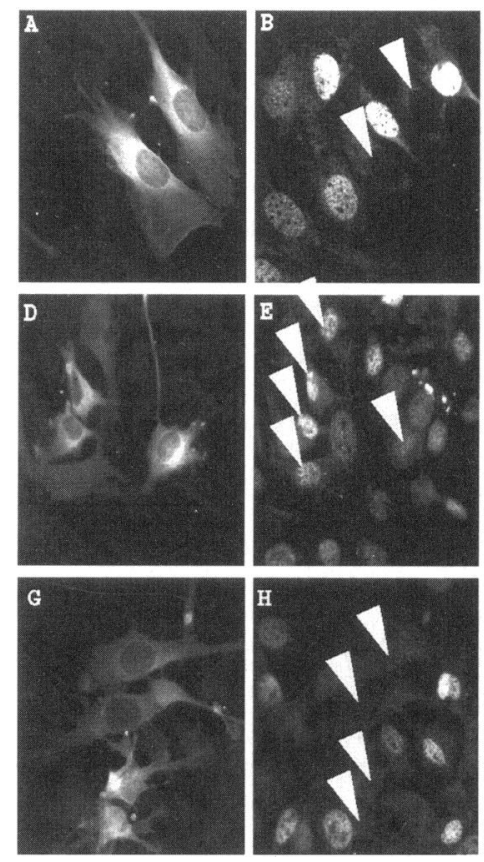

Hoechst
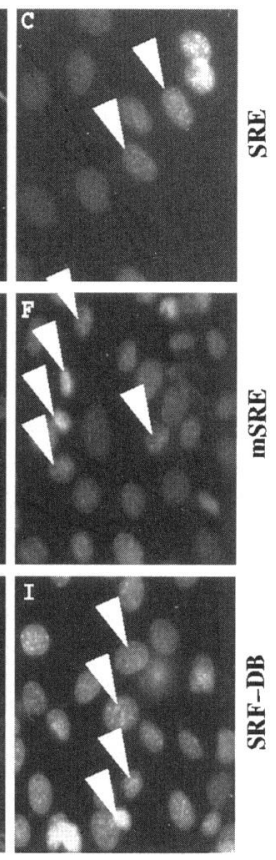

Figure 1. SRF inhibition through microinjection of SRE oligonucleotide or purified SRF-DB blocks MyoD expression in C2C12 myoblasts kept in proliferating conditions. (A) Schematic representation of the timing of microinjection and immunofluorescence done in part B. (B) Proliferating C2C12 myoblasts were microinjected with a solution of rabbit marker antibody containing either SRE oligonucleotide (A-C), mutated SRE oligonucleotide (D-F) or purified SRF-DB (G-I). Four hours after microinjection, cells were fixed and stained for microinjected marker rabbit antibodies (A, D, and G), MyoD expression (B, E, and H), and DNA (C, F, and I). 
ure 1B, panels C, F, and I). As a control, mutated SRE oligonucleotides (in which the key nucleotides for SRF binding have been mutated) were injected (Figure $1 B$, panel D) and did not result in any inhibition of MyoD expression (Figure 1B, panel E). Similarly, when SRF activity is inhibited after injection of purified SRF-DB (Figure 1B, panel G) no MyoD expression is detected in injected cells $4 \mathrm{~h}$ after injection (Figure 1B, panel H). SRE oligonucleotide or purified SRF-DB were also microinjected into C2 myoblasts, the parental cell line from which $\mathrm{C} 2 \mathrm{C} 12$ cells were derived. As in $\mathrm{C} 2 \mathrm{C} 12, \mathrm{SRF}$ inhibition in $\mathrm{C} 2$ cells prevented MyoD expression (our unpublished observations). However, because $\mathrm{C} 2 \mathrm{C} 12$ cells express higher levels of $\mathrm{MyoD}$, they represent a better model than the $\mathrm{C} 2$ cell line for these experiments and we continued our studies only in C2C12.

We next examined whether microinjection of antibodies against SRF affected MyoD expression. We have shown in previous studies that anti-SRF antibodies, microinjected in the cytoplasm, bind newly synthesized SRF thus preventing it from going into the nucleus (Gauthier-Rouviere et al., 1991a). As such, inhibition of SRF activity occurs only after the degradation of the preexisting nuclear pool of SRF, which we have show to take 10-12 h. As shown in Figure 2B, cytoplasmic injection of anti-SRF (Figure 2B, panel A) completely abolishes SRF nuclear staining (Figure 2B, panel B) $20 \mathrm{~h}$ after injection. Figure $2 \mathrm{~B}$, panels D and E, show that the inhibition of SRF by anti-SRF injection (Figure 2B, panel D) resulted in an absence of detectable MyoD protein (Figure 2B, panel E), whereas microinjection of preimmune antiserum has no effect either on SRF or MyoD expression (our unpublished observations). As an additional control we have verified that cytoplasmic microinjection of anti-SRF in late G1 did not affect the distribution of another nuclear protein; cyclin A (our unpublished observations).

To estimate more precisely the time at which MyoD expression decreases after SRF inhibition, cells were fixed 2, 4, and $6 \mathrm{~h}$ after microinjection of SRE oligonucleotide or purified SRF-DB. These relatively short time points were chosen because of the very short half-life of MyoD protein (MyoD protein turnover is 60-90 min). As summarized in Figure 3, microinjection of SRE oligonucleotide or SRF-DB induces a rapid decrease in MyoD expression. Indeed, after $2 \mathrm{~h}$, only $28 \%$ of cells injected with SRE oligonucleotide and $31 \%$ of cells injected with SRF-DB still show a detectable level of staining for MyoD. Six hours after SRF inhibition, this had fallen to $18 \%$ of cells injected with SRE oligonucleotide and $14 \%$ of cells injected with SRF-DB. In contrast, at the different times tested (i.e., 2,4 , and $6 \mathrm{~h}$ ), $70 \%$ of cells injected with mutated inactive SRE oligonucleotide still expressed MyoD, showing that microinjection had no significant effect on MyoD expression (80\% of the surrounding nonin- jected cells express MyoD). Analyzing longer time periods after microinjection revealed that MyoD expression was repressed for $8 \mathrm{~h}$ after microinjection, beginning to resume $10 \mathrm{~h}$ after SRE oligonucleotide injection and $12 \mathrm{~h}$ after SRF-DB injection (our unpublished observations). This result indicates that the effect we observed by microinjection of SRE or SRF-DB is fully reversible in a time that likely corresponds to the half-life of SRE and SRF-DB inside living cells.

To confirm these observations, we used the anti-6/ C2CL2 cell model recently developed (Soulez et al., unpublished data). The anti- 6 clone is derived from C2C12 cells that have been stably transfected by both a long terminal repeat-glucocorticoid receptor (LTRGR) plasmid that encodes the glucocorticoid receptor (cells called C2CL2) and a plasmid that contains the SRF CDNA in an antisense orientation under the control of the GR element (anti-6). Addition of dexamethasone to the culture medium activates the expressed glucocorticoid receptor in turn in anti- 6 cells, inducing antisense SRF expression. As observed with injection of antibodies, the inhibition of endogenous SRF was assumed to be complete only after $12 \mathrm{~h}$ of dexamethasone induction by which time endogenous SRF was degraded. We investigated the effect of dexamethasone treatment on the expression of MyoD in both C2CL2 and anti- 6 cells. Both C2CL2 and anti-6 myoblasts were grown either in proliferating medium alone or supplemented with the glucocorticoid dexamethasone $\left(10^{-6} \mathrm{M}\right)$. After 3 days, cells were fixed and analyzed for SRF and MyoD expression by immunofluorescence as detailed in Figure 4A. Figure 4B shows SRF expression in parental C2CL2 cells (Figure 4B, panel A). As expected from previous studies SRF is expressed ubiquitously in the nucleus. Treatment of C2CL2 cells with dexamethasone (Figure 4B, panel C) resulted in a slight increase in SRF staining. As shown in Figure 4B, panel B, MyoD is expressed in approximately $80 \%$ of the C2CL2 myoblasts, an expression slightly increased after dexamethasone treatment (between $80-85 \%$ of MyoD expressing cells; $83 \%$ in Figure 4B, panel D). Analysis of anti-6 cells (C2CL2 cells containing inducible antisense SRF) shows that SRF is still expressed in nontreated anti- 6 cells (Figure 4B, panel E). Compared with the parental cell line a slight diminution in SRF staining is detectable in the untreated anti- 6 cells (Figure $4 \mathrm{~B}$, compare panel $\mathrm{A}$ to panel E). This diminution is also observable by quantification of the mRNA of C2CL2 and anti- 6 myoblasts (Soulez et al., unpublished data) and has been attributed to an endogenous activation of the LTR-MMTV promoter leading to a slight leak of antisense SRF in these cells. The addition of dexamethasone induces a pronounced diminution of SRF. This is shown in panel $\mathrm{G}$ where little or no SRF is detectable by immunofluorescence. MyoD staining in untreated anti- 6 myoblasts is also already diminished in comparison to the 


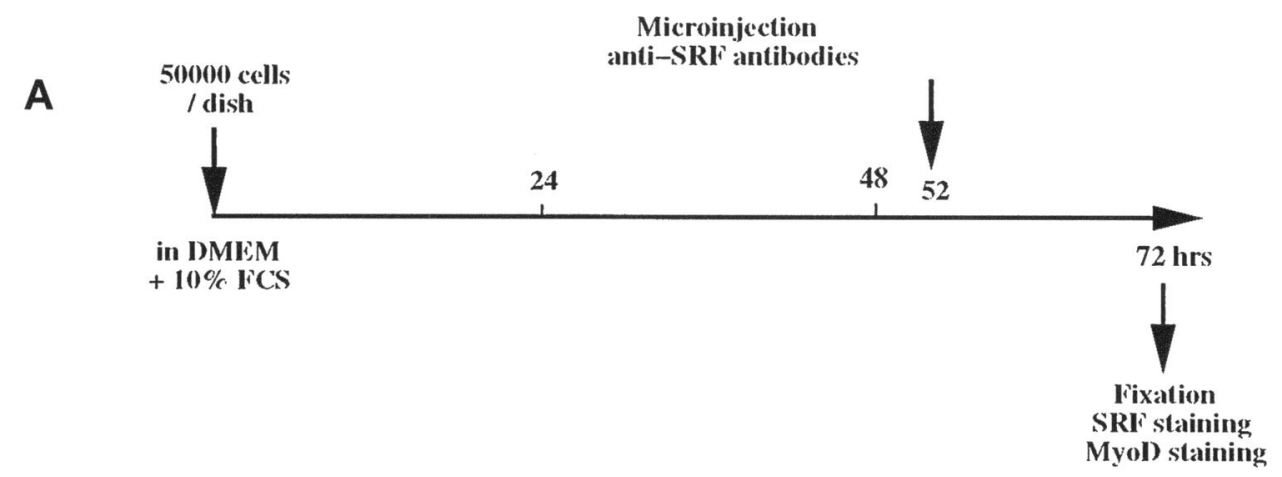

B

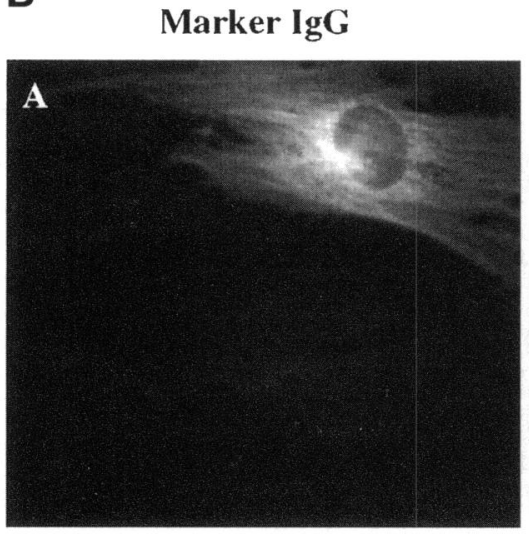

Marker IgC

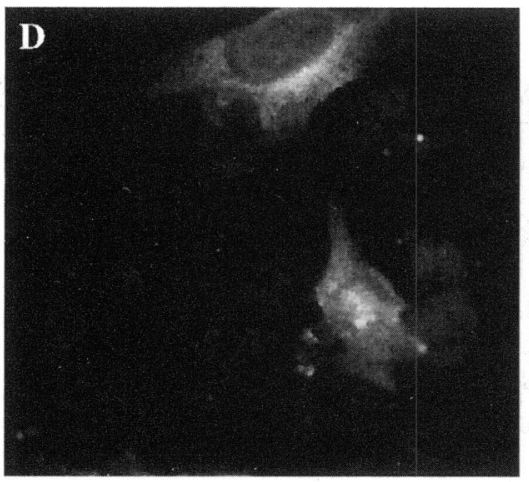

SRF

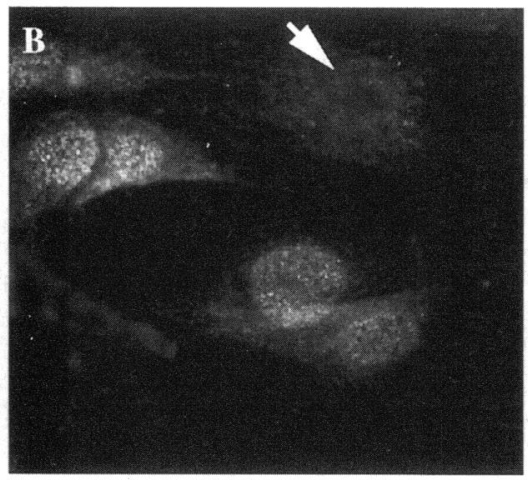

MyoD

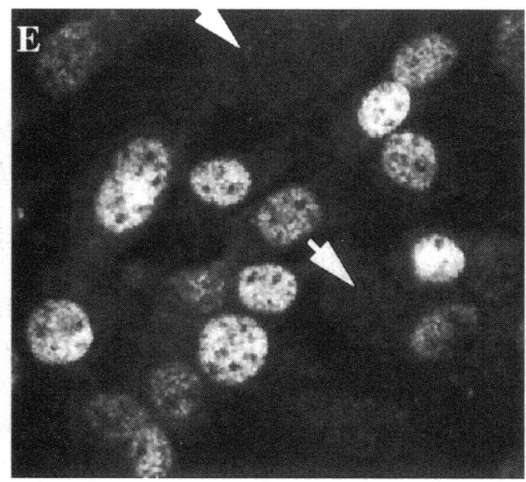

Hoechst

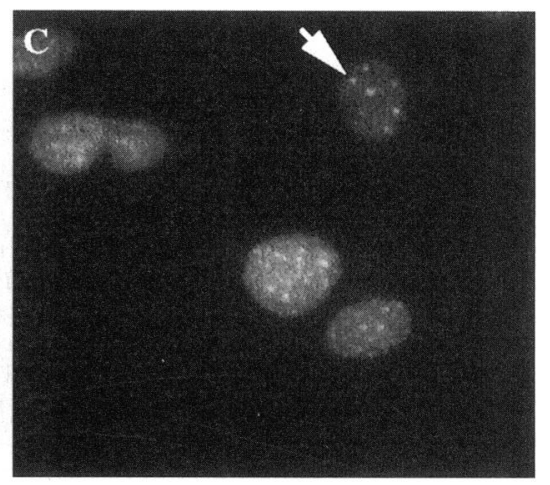

Hoechst

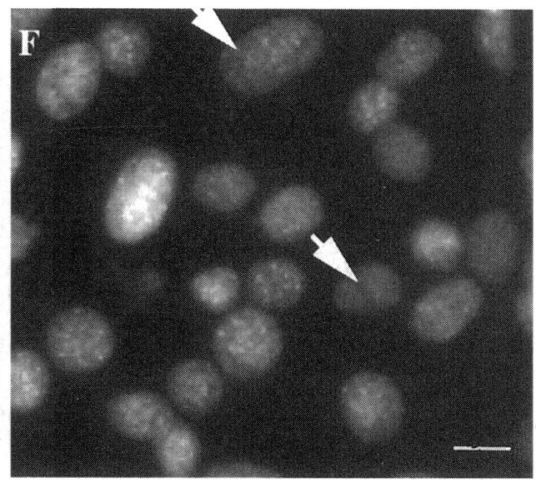

Figure 2. SRF inhibition through microinjection of anti-SRF antibodies blocks MyoD expression in subconfluent C2C12 kept in proliferating conditions. (A) Schematic representation of the timing of microinjection and immunofluorescence done in part B. (B) Subconfluent proliferating $\mathrm{C} 2 \mathrm{C} 12$ myoblasts were microinjected with affinity-purified rabbit anti-SRF antibodies. Twenty hours later, cells were fixed and stained for injected marker rabbit antibodies (A and D), SRF expression (B), MyoD expression (E), and DNA (C and F).

MyoD level in C2CL2 myoblasts (Figure 4B, compare panel F, $60 \%$ of MyoD expressing cells, to panel B, $80 \%$ of MyoD expressing cells). This can most likely be attributed to the leak of the antisense SRF in the anti-6 myoblasts. However, when anti- 6 cells are treated with dexamethasone to induce antisense SRF, there is a concomitant decrease in the level of MyoD (Figure $4 \mathrm{~B}$, panel $\mathrm{H}, 0 \%$ of $\mathrm{MyoD}$ expressing cells) as SRF expression falls (Figure 4B, panel G). This suppression of MyoD expression after dexamethasone treatment cannot be attributed to an effect of the dexamethasone other than induction of SRF antisense because the parental cell line (which was transfected with the LTR-GR only) does not show such inhibition of MyoD expression upon dexamethasone treatment (Figure 4B, panel D). As soon as SRF level is diminished MyoD expression falls (Figure 4B, compare panels A and B to $E$ and $F$ ) and becomes undetectable when SRF expres- 


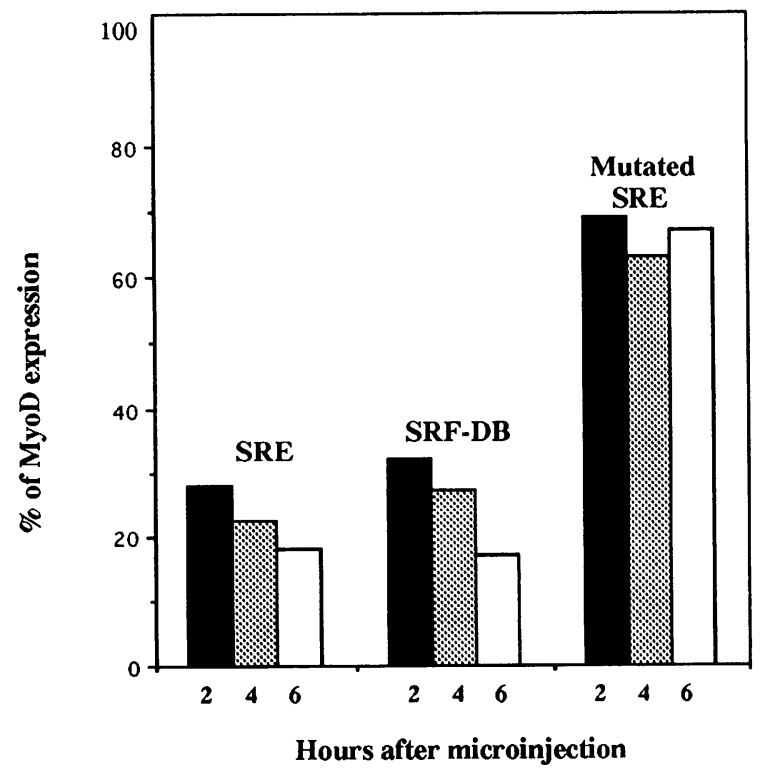

Figure 3. Inhibitory effect of SRE oligonucleotide or SRF-DB microinjection in proliferating $\mathrm{C} 2 \mathrm{C} 12$ myoblasts on MyoD expression. Subconfluent proliferating $\mathrm{C} 2 \mathrm{C} 12$ myoblasts were injected as described in Figure 1, fixed 2 (black), 4 (dotted), or $6 \mathrm{~h}$ (white) after injection and stained for microinjected rabbit antibodies and MyoD expression. The percentage of injected cells expressing MyoD was measured. The histogram summarizes the data from six independent sets of experiments; 40 to 50 cells were injected in each experiment.

sion is fully abolished (Figure $4 \mathrm{~B}$, panels $\mathrm{G}$ and $\mathrm{H}$ ). To confirm that the expression of both SRF and MyoD was inhibited in SRF antisense-induced C2CL12 cells, mRNA levels were analyzed by Northern blot. $\operatorname{Poly}(\mathrm{A})^{+}$RNA were isolated from anti- 6 cells treated or not treated with dexamethasone and placed in differentiation medium. In cells treated with dexamethasone, the two forms of SRF mRNA were significantly reduced, the $2.4 \mathrm{~kb}$ form being undetectable. A similar marked reduction of the transcripts for MyoD was observed in SRF antisense-induced cells. Taken together these results show that inhibition of SRF expression with an antisense SRF, like inhibition of its activity by microinjection, results in a complete shutdown of MyoD expression in subconfluent proliferating myoblasts.

\section{Inhibition of SRF Activity in C2C12 Cells Cultured under Differentiating Conditions Suppresses MyoD Expression}

The data reported above clearly show that inhibition of SRF in proliferating $\mathrm{C} 2 \mathrm{C} 12$ myoblasts leads to the rapid decrease and abolition of MyoD expression. To investigate whether such effects also take place after $\mathrm{C} 2 \mathrm{C} 12$ have ceased to proliferate, we further examined the effect of SRF inhibition on MyoD expression in cells placed in differentiating medium for several hours. C2C12 myoblasts were allowed to proliferate in growth medium until confluence before being induced to differentiate by replacing the growth medium by differentiation medium. At different times thereafter, differentiating mononucleated $\mathrm{C} 2 \mathrm{C} 12$ cells were microinjected with either SRE oligonucleotide, SRF-DB domain, or mutated SRE oligonucleotide. Cells were fixed 2, 4, or $6 \mathrm{~h}$ after microinjection and processed for detection of MyoD expression. Figure 5 shows the results of experiments in which cells were microinjected 24,48 , or $60 \mathrm{~h}$ after induction of differentiation and fixed $4 \mathrm{~h}$ after microinjection. Under these conditions, microinjection of SRE oligonucleotide strongly inhibited MyoD expression. In contrast, in the control experiment in which myoblasts were injected with mutated SRE oligonucleotide, no inhibition of MyoD expression was observed. SRF inhibition through microinjection of SRF-DB also abolished MyoD expression. Interestingly, the later the microinjections were performed after addition of differentiation medium, the more pronounced was the inhibition of MyoD. In cells placed in differentiation medium for $60 \mathrm{~h}$, no MyoD expression was detected $4 \mathrm{~h}$ after microinjection. In these experiments, only mononucleated cells were microinjected. Indeed, $36 \mathrm{~h}$ after induction of differentiation by addition of the differentiation medium, plurinucleated myotubes are already present (about $40 \%$ of myotubes). Taken together, these data show that inhibition of SRF expression or activity in differentiating myoblasts blocks expression of MyoD. Moreover, the efficiency with which inhibition of SRF shuts down MyoD expression seems to increase with the time spent in differentiation medium.

\section{DISCUSSION}

We have examined the potential implication of SRF in the regulation of the expression of the myogenic regulator MyoD. Through a combination of four approaches leading to either inhibition of SRF activity (i.e., microinjection of anti-SRF antibodies, SRE oligonucleotides, or purified SRF-DB) or expression (inducible antisense SRF-expressing cell line), we have shown the complete shutdown of MyoD expression in $\mathrm{C} 2 \mathrm{C} 12$ cells. This absence of MyoD expression after inhibition of SRF expression or activity is observed both in subconfluent proliferating myoblasts and in mononucleated differentiating $\mathrm{C} 2$ and $\mathrm{C} 2 \mathrm{C} 12$ cells. This regulation of MyoD expression by SRF could explain the early requirement of $\mathrm{SRF}$ in myogenesis.

\section{SRF Expression or Activity Is Required for MyoD Expression}

In addition to its well known function in immediate early gene expression, SRF binding to CArG boxes is 
A

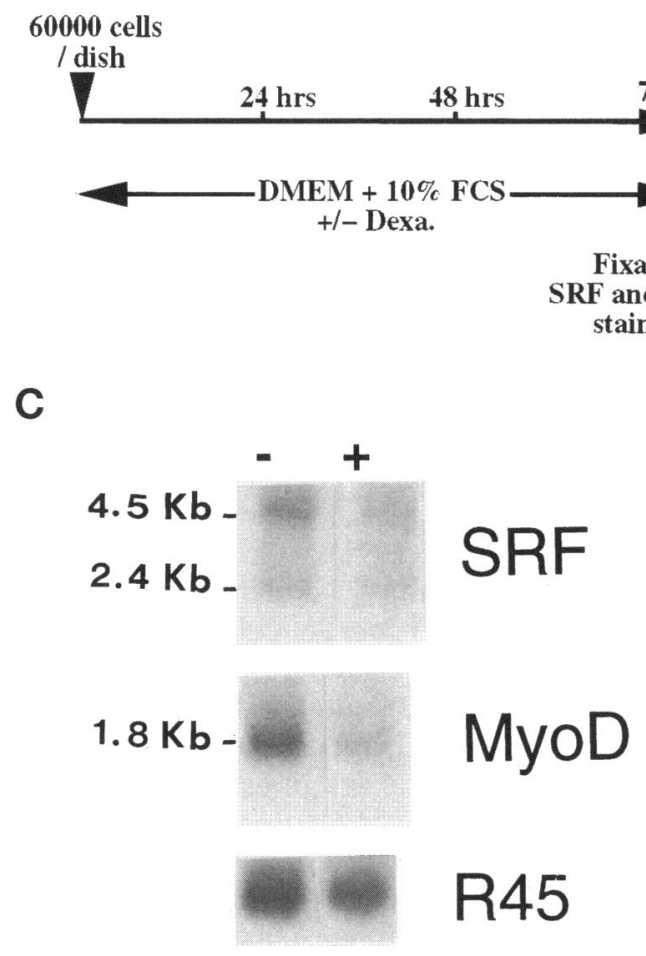

Figure 4. SRF inhibition through expression of antisense SRF abolishes MyoD expression in myoblasts cultured under proliferating conditions. (A) Schematic representation of the timing of antisense induction and immunofluorescence done in part B. (B) C2CL2 and anti-6 cells were plated at 60,000 cells/dish in DMEM supplemented with $10 \%$ fetal calf serum with or without dexamethasone $\left(10^{-6} \mathrm{M}\right)$. Thirty-six hours after plating, dexamethasone was added to the cells without changing the culture medium. Cells were fixed 3 days after plating and stained for SRF and MyoD expression as described in MATERIAL AND METHODS. Shown are immunofluorescent images of SRF (A, C, E, and G) and MyoD staining (B, D, F, and H). (A-D) C2CL2 myoblasts; C and D, treated with dexamethasone. (E-H) anti-6 myoblasts; $\mathrm{G}$ and $\mathrm{H}$, treated with dexamethasone. (C) Poly(A) ${ }^{+}$RNA were prepared from anti- 6 cells cultured in proliferation medium for 3 days and in differentiation medium for 2 days with or without dexamethasone $\left(10^{-6} \mathrm{M}\right)$. Northern blots were performed using human SRF C-terminal fragment, mouse MyoD, and $\mathrm{R} 45$ human $18 \mathrm{~S}$ fragment CDNA as probes. Shown are autoradiographs after hybridation.

involved in the tissue-specific expression of muscle genes (Miwa and Kedes, 1987; Walsh and Shimmel, 1988). Several studies have demonstrated that SRF binds to CArG box sequences present in the promoter of skeletal as well as cardiac muscle genes (Boxer et al., 1988; Papadopoulos and Crow, 1993). Moreover, inhibition of SRF activity following microinjection of anti-SRF antibodies into C2 and L6 myoblasts blocks the cells in a mononucleated undifferentiated state and prevents expression of two muscle-specific markers myogenin and troponin $\mathrm{T}$ (Vandromme et al., 1992). Although the myogenin promoter contains one such CArG-box, it was
B
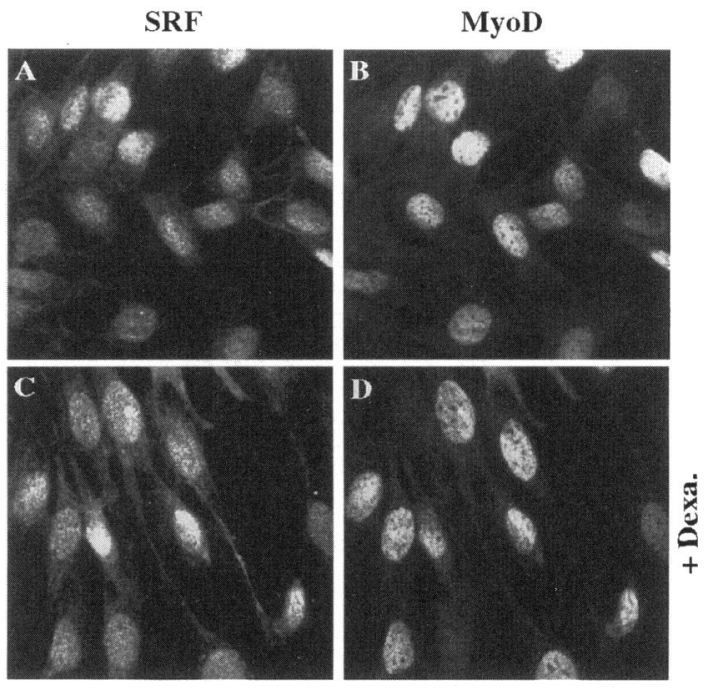

$\mathrm{C} 2 \mathrm{Cl} 2$
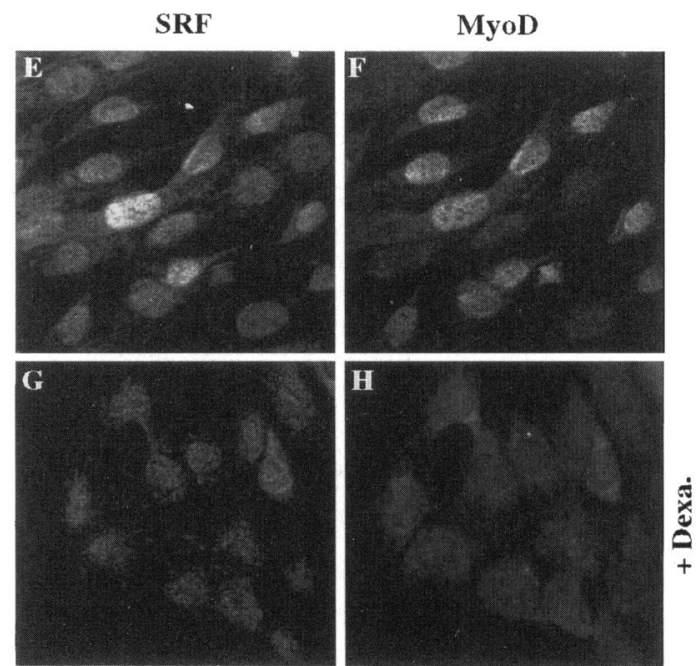

anti 6

shown to be nonfunctional both in muscle and in nonmuscle cells (Santoro and Walsh, 1991). This observation led us to examine the expression of a upstream effector of myogenin expression, Myod. Our microinjection experiments show that the expression or activity of SRF is required continuously for expression of MyoD in both dividing and differentiating $\mathrm{C} 2 \mathrm{C} 12$ myoblasts. In contrast to myogenin and MRF4, which are induced in the course of differentiation, MyoD expression is constitutive in both myoblasts and myotubes (Tapscott et al., 1988). It is required to promote the differentiated phenotype and can elicit a muscle determination in vitro 

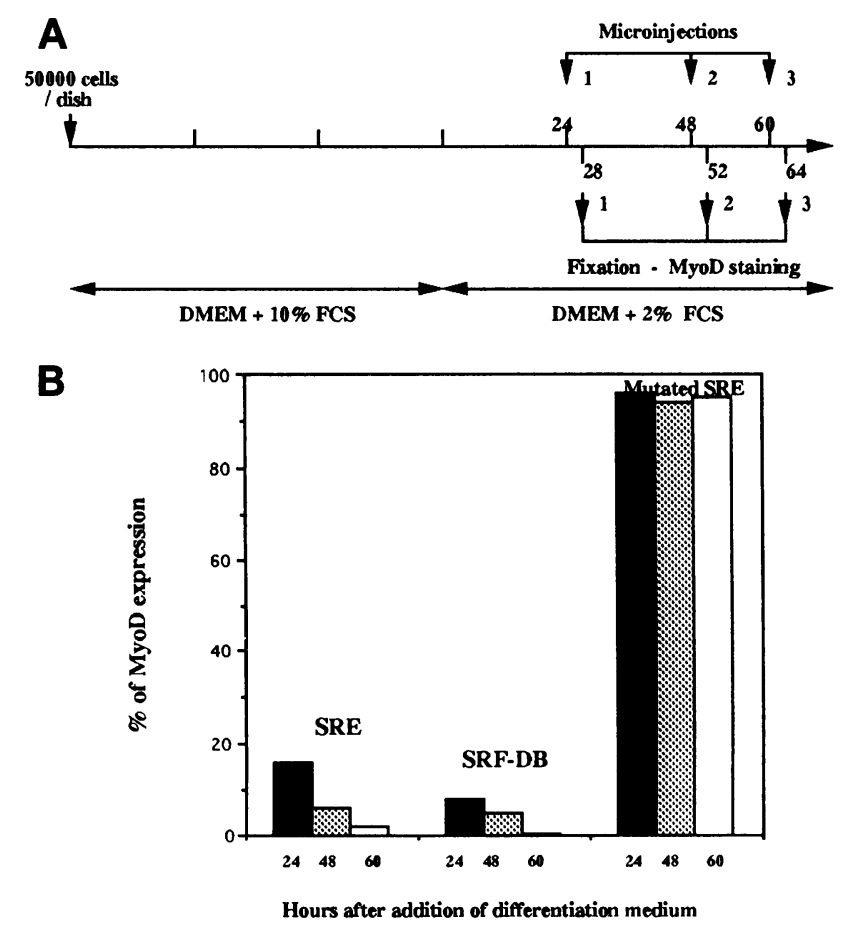

Figure 5. Inhibitory effect of SRE oligonucleotide or SRF-DB microinjection on $\mathrm{MyoD}$ expression in $\mathrm{C} 2 \mathrm{C} 12$ myoblasts placed in differentiation medium. (A) Schematic representation of the timing of microinjection and immunofluorescence done in part B. (B) $\mathrm{C} 2 \mathrm{C} 12$ myoblasts were cultured in proliferation medium for 3 days and then induced to differentiate by replacing the proliferation medium by differentiation medium. After either 24 (black), 48 (dotted), or $60 \mathrm{~h}$ (white) in differentiation medium, cells were microinjected with either SRE oligonucleotide, purified SRF-DB, or mutated SRE oligonucleotide. Four hours after microinjection, cells were fixed and stained for MyoD expression. The percentage of injected cells expressing MyoD was measured. The histogram summarizes the data from six independent sets of experiments; $40-50$ cells were injected in each experiment.

program in a number of nonmuscle cell types (Lassar et al., 1986; Tapscott et al., 1988; Choi et al., 1990).

Our finding that SRF activity is required for MyoD expression provides a target mechanism of the early requirement for SRF in myogenesis we described before (Vandromme et al., 1992).

We found that the inhibition of MyoD expression was less marked when SRF inhibition was performed in subconfluent proliferating myoblasts (with $20-30 \%$ of cells still expressing MyoD). In contrast, the inhibition of MyoD expression by SRF was complete in differentiating $\mathrm{C} 2 \mathrm{C} 12$ cells (i.e., in differentiating medium for $48 \mathrm{~h}$ ). We have observed that the efficiency with which SRF inhibition led to an absence of MyoD expression increases with the time spent in differentiating medium. This effect might be related to the fact that dividing myoblasts show a heterogeneous expression of MyoD (i.e., MyoD is expressed at different levels in proliferat- ing myoblasts), a heterogeneity attributed to a cycledependent expression of MyoD. Cells are committed to differentiate and withdraw from the cell cycle at the end of G1 phase (Nadal-Girard, 1978), a time when MyoD expression is maximum. One explanation for the incomplete inhibition of MyoD expression that we observed in proliferative myoblasts could be that the susceptibility of MyoD expression to SRF levels is dependent on the cell cycle with a maximum inhibition of MyoD by SRF inhibition when MyoD levels are the highest (end of G1).

In addition to SRF, among the proteins of the MADS-box family are the four MEF2 proteins that bind the consensus $(\mathrm{C} / \mathrm{T}) \mathrm{TA}(\mathrm{T} / \mathrm{A})_{6} \mathrm{TA}(\mathrm{G} / \mathrm{A})$ present in many, if not all, muscle gene regulatory regions (Cserjesi and Olson, 1991). MEF2A and MEF2C are specific to differentiated skeletal (and cardiac for MEF2A) muscle and nerve cells ( $Y u$ et al., 1992). MEF2A expression is concomitant with the early expression of sarcomeric proteins during myogenesis in vitro, whereas MEF2C appears only later. MEF2D is also restricted to muscle cell lineages and in contrast to MEF2A and MEF2C, it is also present in proliferating myoblasts (Breitbart et al., 1993). Considering the possible implication of MEF2D in the early commitment events leading to myogenesis, as well as the sequence homology between MEF2D and SRF, one may question whether our tools initially designed to specifically affect SRF activity, may also have an effect on MEF2D. However, this could not be the case because of the following: 1) SRF and MEF2 binding sites are clearly different, and in particular it was shown that binding of MEF2C to the MEF2 site was not affected by the presence of CArG box sequences (McDermott $e t$ al., 1993). 2) MEF2 proteins do not bind the CArG box. 3) Amino acids 138-142 have been reported to be essential for specific binding of SRF to the SRE sequence (Nurrish and Treisman, 1995). These residues are present in SRF-DB (which spans to amino acids 113-265), effectively discounting an effect of SRF-DB on activity of the MADS-box family members other than SRF.

\section{How Does SRF Control MyoD Expression?}

Our results demonstrate that SRF expression and activity are required for MyoD expression, an effect sufficient to explain the early requirement of SRF in myogenesis. This observation raises the question of how SRF modulates MyoD expression. Different mechanisms can be proposed. Simplistically SRF may directly regulate MyoD expression through SRF-binding sites present in the MyoD promoter. Analysis of the primary nucleotide sequence of MyoD promoter (Tapscott et al., 1992) reveals seven putative CArGlike boxes present in both the proximal and the distal regulatory region. Although the CArG-like 
boxes diverge variably from the consensus CArG sequence, one of them is fully homologous with a CArG sequence present in the promoter region of the mouse myosin light-chain 1A gene, which is capable of binding SRF as efficiently as the wildtype CArG sequence (Catala et al., 1995). The large distance between some of the CArG-like boxes (essentially those of the distal regulatory region) and the transcription initiation site may not be a restriction because recently a functional SRE has been identified in the mouse junB gene $2 \mathrm{~kb}$ upstream of the site of transcription initiation (Perez-Albuerne et al., 1993), indicating that SREs may exert any influence over long distances in an enhancer-like manner.

Alternatively, the expression of MyoD in cultured C2C12 muscle cells may involve the interaction of one or more muscle-specific factors with a general transcription factor binding at the TATA motif. This kind of mechanism has been proposed for transcriptional regulation of Xenopus MyoDa (Leibham et al., 1994; Wong et al., 1994), which involve interactions between the general transcription factor TFIID and a muscle-specific factor MEF2. Interestingly, it has been reported that a related factor TFIIF binds SRF and significantly modulates SRF-activated transcription in vitro (Zhu et al., 1994; Jolliot et al., 1995). Because TFIID has been proposed to bind SRF (Zhu et al., 1991), the possibility remains that SRF bound to a potential CArG-like box of the MyoD promoter interacts with either TFIID or TFIIF to promote transcriptional activation. Another possibility would be that SRF, by directly binding to TFIID or TFIIF, induces recruitment of RNA pol II to the initiation complex or changes the conformation of a large preexisting complex independently of any binding to CArG sequence. Alternatively, if the CArG-like boxes in MyoD promoter turn out to be nonfunctional, SRF may be required for the expression of another transcription factor, itself involved in $\mathrm{MyoD}$ transcription. Because MyoD proteins have a very rapid turnover-less than $60 \mathrm{~min}$ according to our experiments of microinjection of the protein (Vandromme et al., 1994)-such an indirect mechanism is conceivable even though we observed a relatively rapid shutdown of MyoD expression (within $2 \mathrm{~h}$ ) after inhibition of SRF activity.

The control that SRF exerts on MyoD expression and the presence of CArG boxes in numerous musclespecific genes implicate SRF in at least two levels of regulation of muscle differentiation: one level in which SRF exerts a continuous control of MyoD expression in both proliferating and mononucleated differentiating muscle cells, and a second level in which SRF is involved in the expression of muscle-specific genes (Mohun et al., 1987) and possibly in coordination with MyoD protein and/or other myogenic factors because several muscle promoters contain $\mathrm{E}$ and CArG boxes in close proximity (Sartorelli et al., 1990; Catala et al., 1995).

\section{ACKNOWLEDGMENTS}

We are grateful to J. Demaille and J.C. Cavadore for support of this work. We thank P. Dias, J. Hallman, and P. Houghton for providing us with anti-MyoD antibodies and $\mathrm{R}$. Treisman for providing us with SRF cDNA. We thank the Association Francaise contre les Myopathies and the Association pour la recherche contre le cancer for financial support.

\section{REFERENCES}

Blau, H.M., Chiu, P., and Webster, C. (1983). Cytoplasmic activation of human nuclear genes in stable heterokaryons. Cell 32, 1171-1180.

Boxer, L.M., Miwa, T., Gustafon, A., and Kedes, L. (1988). Identification and characterization of a factor that binds to two human sarcomeric actin promoters. J. Biol. Chem. 264, 1284-1292.

Breitbart, R.E., Liang, C.S., Smoot, L.B., Laheru, D.A., Mahdavi, V., and Nadal-Ginard, B. (1993). A fourth human MEF2 transcription factor, hMEF2D, is an early marker of the myogenic lineage. Development 118, 1095-1106.

Catala, F., Wanner, R., Barton, P., Cohen, A., Wright, W., and Buckingham, M. (1995). A skeletal muscle-specific enhancer regulated by factors binding to $\mathrm{E}$ and $\mathrm{CArG}$ boxes is present in the promoter of the mouse myosin light-chain 1A gene. Mol. Cell. Biol. $15,4585-4596$.

Choi, J., Costa, M.L., Mermelstein, C.S., Chagas, C., Holtzer, S., and Holtzer, H. (1990). MyoD converts primary dermal fibroblasts, chondroblasts, smooth muscle, and retinal pigmented epithelial cells into striated mononucleated myoblasts and multinucleated myotubes. Proc. Natl. Acad. Sci. USA 87, 7988-7992.

Concordet, J.P., Salminen, M., Demignon, J., Moch, C., Maire, P., Kahn, A., and Daegelen, D. (1993). An opportunistic promoter sharing regulatory sequences with either a muscle-specific or a ubiquitous promoter in the human Aldolase A gene. Mol. Cell. Biol. 13, 9-17.

Cserjesi, P., and Olson, E.N. (1991). Myogenin induces the myocytespecific enhancer binding factor MEF-2 independently of other muscle-specific gene products. Mol. Cell. Biol. 11, 4854-4862.

Ernt, H., Walsh, K., Harrison, C.A., and Rosenthal, N. (1991). The myosin ligh chain enhancer and the skeletal actin promoter share a binding site for factors involved in muscle-specific gene expression. Mol. Cel. Biol. 11, 3735-3744.

Gauthier-Rouviere, C., Basset, M., Blanchard, J.M., Cavadore, J.C., Fernandez, A., and Lamb, N.J.C. (1991a). Casein kinase II induces c-fos expression via the serum response element pathway and p67SRF phosphorylation in living fibroblasts. EMBO J. 10, 29212930 .

Gauthier-Rouviere, C., Caï, Q.Q., Lautredou, N., Fernandez, A., Blanchard, J.M., and Lamb, N.J.C. (1993). Expression and purification of the DNA-binding domain of SRF: SRF-DB, a part of a DNA-binding protein which can act as a dominant negative mutant in vivo. Exp. Cell Res. 209, 208-215.

Gauthier-Rouviere, C., Cavadore, J.C., Blanchard, J.M., Lamb, N.J.C., and Fernandez, A. (1991b). p67SRF is a constitutive nuclear protein implicated in the modulation of genes required throughout the G1 period. Cell Regul. 2, 575-588. 
Gilman, M.Z., Wilson, R.N., and Weinberg, R.A. (1986). Multiple protein binding sites in the 5 '-flanking region regulate $c$-fos expression. Mol. Cell. Biol. 6, 4305-4316.

Joliot, V., Demma, M., and Prywes, R. (1995). Interaction with RAP74 subunit of TFIIF is required for transcriptional activation by serum response factor. Nature 373, 632-635.

Klamut, H.J., Gangopadhyay, S.B., Worton, R.G., and Ray, P.N. (1990). Molecular and functional analysis of the muscle-specific promoter region of the Duchenne muscular dystrophy gene. Mol. Cell. Biol. 10, 193-205.

Lassar, A.B., Davis, R.L., Wright, W.E., Kadesch, T., Murre, C., Voronova, A., Baltimore, D., and Weintraub, H. (1991). Functional activity of myogenic $\mathrm{HLH}$ proteins requires hetero-oligomerization with E12/E47-like proteins in vivo. Cell 26, 305-315.

Lassar, A.B., Paterson, B.M., and Weintraub, H. (1986). Transfection of a DNA locus that mediates the conversion of $10 \mathrm{~T} 1 / 2$ fibroblasts to myoblasts. Cell 47, 649-656.

Leibham, D., Wong, M.W., Cheng, T.C., Schroeder, S., Weil, P.A., Olson, E.N., and Perry, M. (1994). Binding of TFIID and MEF2 to the TATA element activates transcription of the Xenopus MyoDa promoter. Mol. Cell. Biol. 14, 686-699.

McDermott, J.C., Cardoso, M.C., Yu, Y.T., Andres, V., Leifer, D., Krainc, D., Lipton, S.A., and Nadal-Ginard, B. (1993). hMEF2C gene encodes skeletal muscle- and brain-specific transcription factors. Mol. Cell. Biol. 13, 2564-2577.

Minty, A., and Kedes, L. (1986). Upstream regions of the human cardiac actin gene that modulate its transcription in muscle cells: presence of an evolutionary conserved repeat motif. Mol. Cell. Biol. $6,2125-2136$

Miwa, T., and Kedes, L. (1987). Duplicated CArG box domains have positive and mutually dependent regulatory roles in expression of the human a-cardiac actin gene. Mol. Cell. Biol. 7, 2803-2813.

Mohun, T., Garrett, N., and Treisman, R. (1987). Xenopus cytoskeletal actin and human c-fos gene promoters share a conserved protein-binding site. EMBO J. 6, 667-673.

Mohun, T.J., Chambers, A.E., Towers, N., and Taylor, M.V. (1991). Expression of genes encoding the transcription factor SRF during early development of Xenopus laevis: identification of a CArG boxbinding activity as SRF. EMBO J. 10, 933-940.

Murre, C., McCaw, P.S., Vaessin, H., Caudy, M., Jan, L.Y., Cabrera, C.V., Buskin, J.N., Hauschka, S.D., Lassar, A.B. and Baltimore, D. (1989). Interactions between heterologous helix-loop-helix proteins generate complexes that bind specifically to a common DNA sequence. Cell 58, 537-544.

Nadal-Ginard, B. (1978). Commitment, fusion and biochemical differentiation of a myogenic cell line in the absence of DNA synthesis. Cell 15, 855-864.

Norman, C., Runswich, M., Pollock, R., and Treisman, R. (1988). Isolation and properties of cDNA clones encoding SRF, a transcription factor that binds to the c-fos serum response element. Cell 55, 989-1003.

Nurrish, S.J., and Treisman, R. (1995). DNA binding specificity determinants in MADS-box transcription factors. Mol. Cell. Biol. 15, 4076-4085.

Papadopoulos, N., and Crow, M.T. (1993). Transcriptional control of the chicken cardiac myosin light-chain gene is mediated by two AT-rich cis-acting DNA elements and binding of serum response factor. Mol. Cell. Biol. 13, 6907-6918.
Perez-Albuerne, E.D., Schatteman, G., Sanders, L.K., and Nathans, D. (1993). Transcriptional regulatory elements downstream of the JunB gene. Proc. Natl. Acad. Sci. USA 90, 11960-11964.

Prywes, R., and Roeder, R.G. (1987). Purification of the c-fos enhancer binding protein. Mol. Cell. Biol. 7, 3482-3489.

Santoro, I.M., and Walsh, K. (1991). Natural and synthetic DNA elements with the CArG motif differ in expression and protein binding properties. Mol. Cell. Biol. 11, 6296-6305.

Sartorelli, V., Webster, K.A., and Kedes, L. (1990). Muscle-specific expression of the cardiac $\alpha$-actin gene requires MyoD1, CArG-box binding factor, and Sp1. Genes Dev. 4, 1811-1822.

Tapscott, S.J., Davis, R.L., Thayer, M.J., Cheng, P.-F., Weintraub, H., and Lassar, A.B. (1988). MyoD1: a nuclear phosphoprotein requiring a myc homology region to convert fibroblasts to myoblasts. Science $242,405-411$.

Tapscott, S.J., Lassar, A.B., and Weintraub, A. (1992). A novel myoblast enhancer element mediates MyoD transcription. Mol. Cell. Biol. 12, 4994-5003.

Taylor, A., Erba, H.P., Muscat, G.E.O., and Kedes, L. (1988). Nucleotide sequence and expression of the human skeletal-actin gene: evolution of functional regulatory domains. Genomics 3, 323-336.

Taylor, M., Treisman, R., Garret, N., and Mohun, T. (1989). Musclespecific (CArG) and serum-responsive (SRE) promoter elements are functionally interchangeable in Xenopus embryos and mouse fibroblasts. Development 106, 67-78.

Treisman, R. (1985). Transient accumulation of c-fos mRNA following serum stimulation requires a conserved $5^{\prime}$ element and c-fos $3^{\prime}$ sequence. Cell 42, 889-902.

Treisman, R. (1987). Identification and purification of a polypeptide that binds to the c-fos serum response element. EMBO J. 6, 27112717.

Treisman, R. (1990). The SRE: a growth factor-responsive transcriptional regulator. Semin. Cancer Biol. 1, 47-58.

Treisman, R., and Ammerer, G. (1991). The SRF and MCM1 transcription factors. Curr. Opin. Genet. Dev. 2, 221-226.

Tuil, D., Clergue, N., Montarras, C., Pinset, C., Kahn, A., and PanDinh-Tuy, F. (1990). CCArGG boxes, cis-acting element with a dual specificity: muscle-specific transcriptional activation and serum responsiveness. J. Mol. Biol. 213, 677-686.

Tuil, D., Soulez, M., Montarras, D., Pinset, C., Kahn, A., and PhanDinh-Tuy, F. (1993). Activation of gene expression via CArG boxes during myogenic differentiation. Exp. Cell Res. 205, 32-38.

Vandromme, M., Carnac, G., Gauthier-Rouviere, C., Fesquet, D., Lamb, N., and Fernandez, A. (1994). Nuclear import of the myogenic factor MyoD requires cAMP-dependent protein kinase activity but not the direct phosphorylation of MyoD. J. Cell Sci. 107, 613-620.

Vandromme, M., Gauthier-Rouviere, C., Carnac, G., Lamb, N.J.C., and Fernandez, A. (1992). Serum response factor p67SRF is expressed and required during myogenic differentiation of both mouse C2 and rat L6 muscle cell lines. J. Cell. Biol. 118, 1489-1500.

Walsh, K., and Schimmel, P. (1988). DNA-binding site for two skeletal actin promoter factors is important for expression in muscle cells. Mol. Cell. Biol. 8, 1800-1802.

Weintraub, H., et al. (1991). The myoD gene family: nodal point during specification of the muscle cell lineage. Science 251, 761-766. 
Wong, M.W., Pisegna, M., Lu, M.F., Leibham, D., and Perry, M. (1994). Activation of Xenopus MyoD transcription by members of the MEF2 protein family. Dev. Biol. 166, 683-695.

Yu, Y.T., Breitbart, R.E., Smoot, L.B., Lee, Y., Mahdavi, V., and Nadal-Ginard, B. (1992). Human myocyte-specific enhancer factor 2 comprises a group of tissue-restricted MADS box transcription factors. Genes Dev. 6, 1783-1798.
Zhu, H., Joliot, V., and Prywes, R. (1994). Role of transcription factor TFIIF in serum response factor-activated transcription. J. Biol. Chem. 269, 3489-3497.

Zhu, H., Roy, A.L., Roeder, R.G., and Prywes, R. (1991). Serum response factor affects preinitiation complex formation by TFIID in vitro. New Biol. 3, 455-464. 